\title{
The Ecology of Medical Care During the COVID-19 Pandemic in Japan: a Nationwide Survey
}

\author{
Takuya Aoki, MD, PhD, MMA ${ }^{1,2}$ @ and Masato Matsushima, MD, PhD, $\mathrm{MPH}^{7}$ \\ 'Division of Clinical Epidemiology, Research Center for Medical Sciences, The Jikei University School of Medicine, Tokyo, Japan; '2Section of Clinical \\ Epidemiology, Department of Community Medicine, Graduate School of Medicine, Kyoto University, Kyoto, Japan.
}

BACKGROUND: The coronavirus disease 2019 (COVID19) pandemic has had a profound impact on health care utilization. However, the overall picture of shifts in health care utilization remains unclear.

OBJECTIVE: We assessed the ecology of medical care during the COVID-19 pandemic in Japan and compared it with the results pre-pandemic. We also investigated the associations of sociodemographic and clinical factors with health care utilization during the COVID-19 pandemic.

DESIGN AND METHODS: We conducted a nationwide cross-sectional survey of a representative sample of the general Japanese adult population in May 2021. The main outcomes were health care utilization for healthrelated events in the last month. We assessed sociodemographic and clinical factors, including age, sex, years of education, annual household income, social isolation, and the number of chronic conditions.

KEY RESULTS: Data were analyzed from 1747 respondents. Over-the-counter drug use, physician's office visits, and hospital outpatient clinic visits decreased drastically during the COVID-19 pandemic compared with pre-pandemic levels. The decrease in the use of medical facilities was especially pronounced among the elderly. Sociodemographic and clinical factors were differently associated with health care utilization during the COVID-19 pandemic. Social isolation and years of education were positively associated with over-the-counter drug use, while female sex was associated with increased over-thecounter drug use and physician's office visits. In addition, the number of chronic conditions was associated with increased hospital visits.

CONCLUSIONS: During the COVID-19 pandemic, the use of medical facilities for health-related events decreased drastically, especially among the elderly. A pharmacy is an important source of health care in a population with social isolation. These findings may be useful to researchers and policymakers in rethinking health care systems during and after the pandemic.

KEY WORDS: COVID-19; delivery of health care; health behavior; Japan.

J Gen Intern Med 37(5):1211-7

DOI: $10.1007 / \mathrm{s} 11606-022-07422-7$

(c) The Author(s) under exclusive licence to Society of General Internal Medicine 2022

\begin{tabular}{l}
\hline \hline Prior Presentations: none \\
\hline \hline Received September 5, 2021 \\
Accepted January 18, 2022 \\
Published online February 7, 2022
\end{tabular}

\section{INTRODUCTION}

The coronavirus disease 2019 (COVID-19) pandemic is considered to have had a profound impact on health care utilization worldwide. Studies conducted early during the pandemic in the USA and Japan have reported that the number of physician's office visits decreased. ${ }^{1-3}$ Another study showed reductions in emergency department and inpatient utilization, as well as outpatient utilization during the early stages of the pandemic. ${ }^{4}$ These changes may be due to governments' implementation of various strategies such as large-scale physical distancing measures and movement restrictions. ${ }^{5}$ Japan has experienced five waves of COVID-19 and recorded 1,723,524 cases and 18,361 deaths as of December 8, 2021, since the epidemic began. ${ }^{6}$ The Japanese government has repeatedly declared a state of emergency and urged its citizens to refrain from going out unnecessarily. In addition to policy factors, individuals' health-seeking behaviors may have changed during the pandemic. However, the overall picture of shifts in health care utilization due to the pandemic remains unclear.

It is useful to describe "the ecology of medical care" as a way to grasp the whole picture of health care utilization. The theory of "the ecology of medical care" was first proposed by White in $1961,{ }^{7}$ providing a framework for understanding patterns of an individual's choices in seeking medical care for health-related events in specific populations of interest in which the number of people among the total population who had utilized medical services in a given period of time is calculated. ${ }^{8}$ This framework was replicated in different countries worldwide and offered a useful tool to researchers and health care policymakers. $^{9-12}$

Japan has a universal health insurance system that provides a comprehensive coverage to all Japanese citizens and has good access to health care services. ${ }^{13}$ In Japan, the ecology of medical care has been investigated in 2003 and 2013. ${ }^{14,15}$ Compared with the 2003 study, the participants in the 2013 study were reported to have fewer physician and emergency room visits and less over-the-counter(OTC) drug use, but reported higher frequency of complementary or alternative medicine (CAM) use. ${ }^{15}$ Thus, health care utilization is changing under the influence of the social background of each era. For example, it can be inferred that social isolation, which is a state of having few social relationships or infrequent social 
contact with others, has had an impact on health care utilization during the pandemic.

Regarding the change in health care utilization due to the COVID-19 pandemic, reevaluating the ecology of medical care may be useful to researchers and policymakers in rethinking health care systems during and after the pandemic. Therefore, this study aimed to assess health care utilization for health-related events in a representative sample of the Japanese general population during the COVID-19 pandemic and to compare it with the results before the pandemic in Japan. The participants in the analysis were divided into elderly and non-elderly groups, based on age, because we hypothesized that health care utilization would differ between the elderly, who were at high risk for severe COVID-19 illness, and the non-elderly groups. In addition, we investigated the associations of sociodemographic and clinical factors with health care utilization during the pandemic. We were particularly interested in the factor of social isolation, which is a major health problem and has increased globally due to the pandemic. ${ }^{16}$ There is consistent evidence linking social isolation with worse cardiovascular and mental health outcomes. ${ }^{17}$ Furthermore, social isolation is also considered to be potentially related to increase in health care utilization. ${ }^{18}$

\section{METHODS}

\section{Design, Setting, and Participants}

We used data collected from the National Usual Source of Care Survey (NUCS), which was conducted in May 2021 during the fourth wave of COVID-19 in Japan. During the fourth wave, there were more than 6000 new cases of COVID-19 daily, more than 100 deaths occurring daily, and a positive test rate of more than $9 \%$, in Japan. ${ }^{19}$ The NUCS was a nationwide mail survey that aimed to collect data on the usual source of primary care, health care utilization, health conditions, health-related quality of life, and sociodemographic characteristics in a representative sample of the Japanese adult population. In the NUCS, a national representative panel in Japan administered by the Nippon Research Center was used to select possible participants. This panel is composed of approximately 70,000 residents who were selected from the Japanese general population using a multistage sampling method and who participated in a previous survey from the Nippon Research Center. ${ }^{20}$ From the panel, 2000 possible participants aged 20-75 years were selected through stratified sampling by age, sex, and residential area. The survey participants received 500 JPY gift certificates. Among residents responding to the NUCS, eligible participants in this study were individuals who responded to the survey item regarding health care utilization. The institutional review board of the Jikei University School of Medicine approved this study (approval no. 32-416(10505)).

\section{Measures}

Health Care Utilization. We collected data on participants' health care utilization using a structured questionnaire (Appendix 1). Participants were asked to answer the following questions about health care utilization for symptoms or injuries in the last month: OTC drug use, physician's office visit, hospital outpatient clinic visit, university medical center visit, emergency room visit, home health care use, CAM use, and hospitalization. We excluded telemedicine visits because telemedicine for new healthrelated events was not widespread in Japan as of May $2021 .^{21}$

Sociodemographic and Clinical Factors. We collected data on the sociodemographic and clinical factors of the participants. The questionnaire measured the age, sex, years of education, annual household income, social isolation, and the number of chronic conditions.

We used the Japanese version of the abbreviated Lubben Social Network Scale (LSNS-6) ${ }^{22}$ to assess social isolation. The LSNS-6 score is an equally weighted sum of six items, and the scores range from 0 to 30 points, with higher scores indicating a better quality of the social network. The reliability and validity of the Japanese version of LSNS- 6 have been assessed in a previous study in Japan. ${ }^{22}$ As suggested in the previous study, we classified patients with a score of $<12$ points as being socially isolated. ${ }^{23}$

We used a validated list of 20 chronic conditions that were created based on previous multimorbidity literature and relevance to the primary care population ${ }^{24}$ : hypertension, depression/anxiety, chronic musculoskeletal conditions that cause pain or limitation, arthritis/rheumatoid arthritis, osteoporosis, chronic respiratory disease (asthma, chronic obstructive pulmonary disease, or chronic bronchitis), cardiovascular disease, heart failure, stroke/transient ischemic attack, stomach problems, colon problems, chronic hepatitis, diabetes, thyroid disorder, any cancer in the past 5 years, kidney disease/failure, chronic urinary problem, dementia/Alzheimer's disease, hyperlipidemia, and obesity.

\section{Statistical Analysis}

Descriptive analyses were performed using the ecology of medical care model. ${ }^{7}$ We estimated the number of persons per 1000 residents who had experienced different health care utilization during a 1-month period and calculated $95 \%$ confidence intervals (CI) for event rates. Subgroup analyses for variables of interest in health care utilization were conducted by age, sex, years of education, annual household income, social isolation, and the number of chronic conditions.

In addition, we descriptively compared each health care utilization of the present study with aggregate data (3787 adults) of the ecology of medical care study conducted in Japan in 2013 using a sampling method similar to the NUCS. ${ }^{15}$ This study is the most recent ecology of medical care study conducted in Japan before the COVID-19 
pandemic. The data used for the study conducted in 2013 were based on health diaries recorded for a month in 2013 by a population-weighted random sample from a nationally representative panel compiled by a commercial survey company. Further details regarding the study design are presented elsewhere. $^{15}$

To investigate the associations of sociodemographic and clinical factors with each health care utilization of the present study, we performed multivariable logistic regression analyses. In the multivariable analyses, we defined a hospital visit as a composite outcome that included hospital outpatient clinic visits, university medical center visits, and emergency room visits, because in Japan, there is a clear institutional distinction between the physician's offices and the outpatient departments/emergency rooms in hospitals and university medical centers. ${ }^{13}$

For each analysis, we used a two-sided significance level of $P=0.05$. For missing independent variables in the regression model, we performed a complete case analysis. Statistical analyses were performed using $\mathrm{R}$ version 4.1.0 (R Foundation for Statistical Computing, Vienna, Austria; www.R-project. org).

\section{RESULTS}

\section{Participants' Characteristics}

Of the 2000 adult residents, 1757 responded to the NUCS (response rate: $87.9 \%$ ). Among them, we excluded 10 participants who did not respond to the survey item regarding health care utilization. Then, we analyzed the remaining 1747 eligible participants. Table 1

Table 1 Participants' Characteristics $(N=1747)$

\begin{tabular}{ll}
\hline \hline Characteristic & $\boldsymbol{n}(\boldsymbol{\%})$ \\
\hline Age, y & \\
$20-29$ & $202(11.6)$ \\
$30-39$ & $293(16.8)$ \\
$40-49$ & $363(20.8)$ \\
$50-64$ & $496(28.4)$ \\
$\geqq 65$ & $393(22.5)$ \\
Gender & \\
Male & $857(49.1)$ \\
Female & $890(50.9)$ \\
Education & \\
Less than or equal to high school & $637(36.5)$ \\
More than high school & $1069(61.2)$ \\
Data missing & $41(2.3)$ \\
Annual household income, million JPY & \\
$<3.00(\fallingdotseq 27,000$ US dollars) & $285(16.3)$ \\
$3.00-4.99$ & $526(30.1)$ \\
$\geqq 5.00$ & $916(52.4)$ \\
Data missing & $20(1.1)$ \\
Social isolation & \\
Absent & $1205(69.0)$ \\
Present & $530(30.3)$ \\
Data missing & $12(0.7)$ \\
Number of chronic conditions & $790(45.2)$ \\
0 & $453(25.9)$ \\
1 & $433(24.8)$ \\
\#2 & $71(4.1)$ \\
\hline Data missing &
\end{tabular}

presents the characteristics of the study population. Of the eligible participants, $22.5 \%$ were elderly ( $\geq 65$ years old), while $30.3 \%$ were considered socially isolated. Approximately half of the participants had one or more chronic conditions. Appendix 2 shows the comparison between the population distribution of Japan's census data and that of the study participants.

\section{Ecology of Medical Care During the Pandemic}

Table 2 shows the monthly number of health care utilization for symptoms or health-related events per 1000 Japanese individuals during the COVID-19 pandemic. The most frequently used health care resources were the physicians' offices. Table 2 also shows the results of subgroup descriptive analyses by age, sex, years of education, annual household income, social isolation, and the number of chronic conditions. The frequency of OTC drug use was higher among non-elderly adults, women, those with more than high school education, those without chronic conditions, and socially isolated individuals. Moreover, women were more likely to report physician's office visits and CAM use. Elderly participants visited university medical centers and CAM and were hospitalized more frequently than non-elderly adults. In addition, participants with one or more chronic conditions visited hospital outpatient clinics, university medical centers, and CAM and were hospitalized more frequently than those without chronic conditions.

\section{Comparison with the Pre-pandemic Study}

Figures 1 and 2 show the comparisons of the results of the present study with the ecology of medical care study conducted in Japan in 2013 before the COVID-19 pandemic. In both non-elderly and elderly groups, the present study showed lower frequencies of OTC drug use, physician's office visits, and hospital outpatient clinic visits than those in the 2013 study. Especially in the elderly group, OTC drug use decreased to approximately one-seventh, and visits to physicians' offices and hospital outpatient clinics decreased to approximately one-third.

\section{Associations of Sociodemographic and Clinical Factors with Health Care Utilization During the Pandemic}

Table 3 shows the results of multivariable logistic regression analyses, examining the associations of sociodemographic and clinical factors with health care utilization during the pandemic, including OTC drug use, physician's office visits, and hospital visits. Social isolation, female sex, and years of education were positively associated with OTC drug use. Female sex was also associated with increased number of physician's office visits. In addition, the number of chronic conditions was positively associated with hospital visits. 
Table 2 Ecology of Medical Care in Terms of Type of Care Stratified by Participants' Characteristics

\begin{tabular}{|c|c|c|c|c|c|c|c|c|}
\hline & \multicolumn{8}{|c|}{ Number per 1000 persons $(95 \% \mathrm{CI})$} \\
\hline & $\begin{array}{l}\text { OTC drug } \\
\text { use }\end{array}$ & $\begin{array}{l}\text { Physician's } \\
\text { office visit }\end{array}$ & $\begin{array}{l}\text { Hospital } \\
\text { outpatient } \\
\text { clinic visit }\end{array}$ & $\begin{array}{l}\text { University } \\
\text { medical } \\
\text { center visit }\end{array}$ & $\begin{array}{l}\text { Emergency } \\
\text { room visit }\end{array}$ & $\begin{array}{l}\text { Home } \\
\text { health } \\
\text { care use }\end{array}$ & CAM use & Hospitalization \\
\hline $\begin{array}{l}\text { Overall } \\
\text { Age }\end{array}$ & $93(80-107)$ & $113(99-129)$ & $37(28-47)$ & $9(5-14)$ & $2(1-6)$ & $2(1-6)$ & $19(14-27)$ & $10(6-16)$ \\
\hline $\begin{array}{l}\text { Age } \\
20-64 \\
\geqq 65\end{array}$ & $\begin{array}{l}104(88-122) \\
53(33-81)\end{array}$ & $\begin{array}{l}113(97-131) \\
115(85-150)\end{array}$ & $\begin{array}{l}34(25-45) \\
46(27-71)\end{array}$ & $\begin{array}{l}7(3-13) \\
15(6-33)\end{array}$ & $\begin{array}{l}2(0-6) \\
3(0-14)\end{array}$ & $\begin{array}{l}3(1-8) \\
0(0-9)\end{array}$ & $\begin{array}{l}17(11-25) \\
28(14-50)\end{array}$ & $\begin{array}{l}6(3-12) \\
23(11-43)\end{array}$ \\
\hline Gender & & & & & & & & \\
\hline $\begin{array}{l}\text { Male } \\
\text { Female }\end{array}$ & $\begin{array}{l}81(63-101) \\
104(85-126)\end{array}$ & $\begin{array}{l}91(73-112) \\
134(113-159)\end{array}$ & $\begin{array}{l}46(33-62) \\
28(18-41)\end{array}$ & $\begin{array}{l}7(3-15) \\
10(5-19)\end{array}$ & $\begin{array}{l}2(0-8) \\
2(0-8)\end{array}$ & $\begin{array}{l}4(1-10) \\
1(0-6)\end{array}$ & $\begin{array}{l}13(6-23) \\
26(16-39)\end{array}$ & $\begin{array}{l}11(5-20) \\
9(4-18)\end{array}$ \\
\hline Education & & & & & & & & \\
\hline $\begin{array}{l}\text { Less than or } \\
\text { equal to high } \\
\text { school }\end{array}$ & $64(47-86)$ & $126(101-154)$ & $49(33-68)$ & $9(3-20)$ & $3(0-11)$ & $3(0-11)$ & $24(13-39)$ & $13(5-25)$ \\
\hline $\begin{array}{l}\text { More than } \\
\text { high school }\end{array}$ & $109(90-129)$ & $105(87-125)$ & $30(21-42)$ & $8(4-16)$ & $2(0-7)$ & $2(0-7)$ & $17(10-26)$ & $8(4-16)$ \\
\hline Annual househ & income, millior & JPY & & & & & & \\
\hline $\begin{array}{l}\quad<3.00(\fallingdotseq \\
\text { 27,000 US } \\
\text { dollars) }\end{array}$ & $81(52-119)$ & $126(90-171)$ & $28(12-55)$ & $14(4-36)$ & $0(0-13)$ & $0(0-13)$ & $32(15-59)$ & $4(0-19)$ \\
\hline $3.00-4.99$ & $87(65-115)$ & $122(95-153)$ & $47(29-67)$ & $8(2-19)$ & $2(0-11)$ & $0(0-7)$ & $23(12-40)$ & $10(3-22)$ \\
\hline$\geqq 5.00$ & $100(82-122)$ & $104(85-125)$ & $35(24-49)$ & $7(2-14)$ & $3(1-10)$ & $4(1-11)$ & $13(7-23)$ & $11(5-20)$ \\
\hline $\begin{array}{l}\text { Social isolation } \\
\text { Absent }\end{array}$ & & & & & & & & \\
\hline Absent & $85(70-103)$ & $116(99-136)$ & $36(26-48)$ & $8(4-15)$ & $2(1-7)$ & $3(1-8)$ & $17(10-26)$ & $10(5-17)$ \\
\hline $\begin{array}{l}\text { Present } \\
\text { Number of chro }\end{array}$ & $111(86-141)$ & $108(82-137)$ & $40(25-60)$ & $2(0-10)$ & $2(0-10)$ & $0(0-7)$ & $26(15-44)$ & $9(3-22)$ \\
\hline Number of chro & conditions & & & & & & & \\
\hline 0 & $111(90-135)$ & $97(78-120)$ & $22(13-34)$ & $4(1-11)$ & $1(0-7)$ & $3(3-9)$ & $13(6-23)$ & $3(3-9)$ \\
\hline 1 & $84(60-113)$ & $126(97-160)$ & $38(22-59)$ & $13(5-29)$ & $4(1-16)$ & $2(0-12)$ & $18(8-34)$ & $15(6-32)$ \\
\hline$\geqq 2$ & $67(45-95)$ & $122(93-157)$ & 69 (47-97) & $12(4-27)$ & $2(0-13)$ & $2(0-13)$ & $32(18-54)$ & $18(8-36)$ \\
\hline
\end{tabular}

OTC over the counter, CAM complementary or alternative medical

\section{DISCUSSION}

This nationwide study of the Japanese adult population revealed that OTC drug use, physician's office visits, and hospital outpatient clinic visits decreased drastically during the COVID-19 pandemic compared with the pre-pandemic levels. The decrease in the use of medical facilities was especially pronounced among the elderly. The present study also found that sociodemographic and clinical factors were differently associated with health care utilization during the pandemic. Social isolation and years of education were positively associated with OTC drug use, while female sex was associated with increased OTC drug use and physician office visits. In addition, the number of chronic conditions was associated with increased hospital visits.

Our findings were consistent with prior studies, showing a decrease in office visits during the early stages of the pandemic. ${ }^{1-3}$ In the present study, using the ecology of medical care model, the number of visits at lower-level medical institutions such as physicians' offices and hospital outpatient clinics, where residents are mainly seen for minor health problems, decreased remarkably compared with the pre-pandemic levels. On the other hand, the number of visits at higher-level medical institutions such as university medical centers and emergency rooms, which accept patients with severe symptoms, and
2013

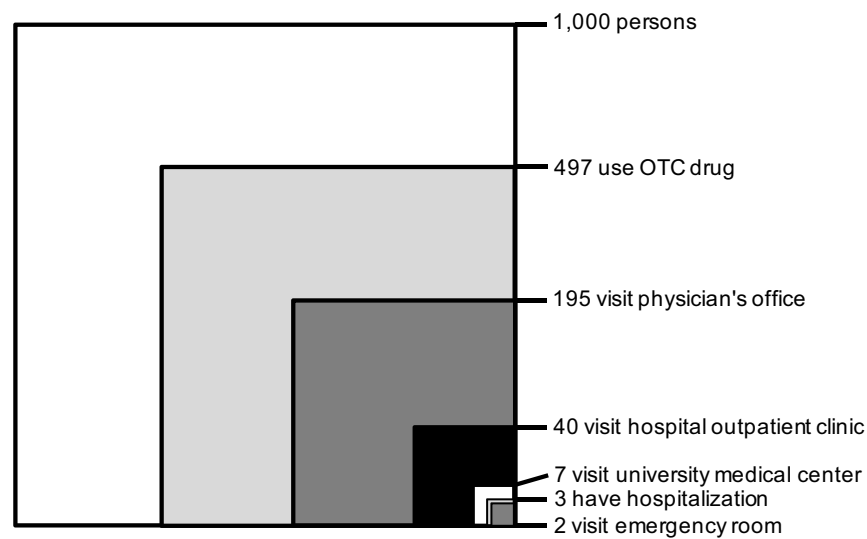

2021

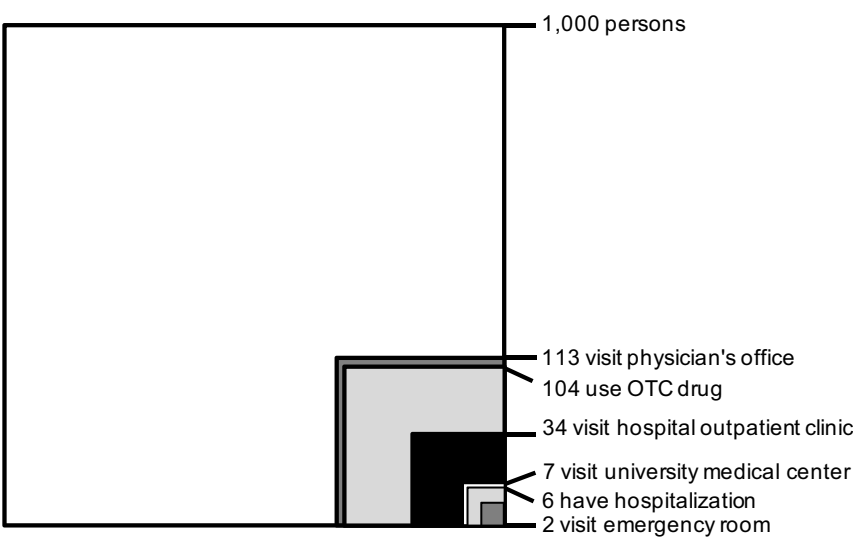

Figure 1 Comparison of health care utilization among non-elderly adults ( $<65$ years old) between the previous study in $2013^{15}$ and the present study in 2021. 
2013

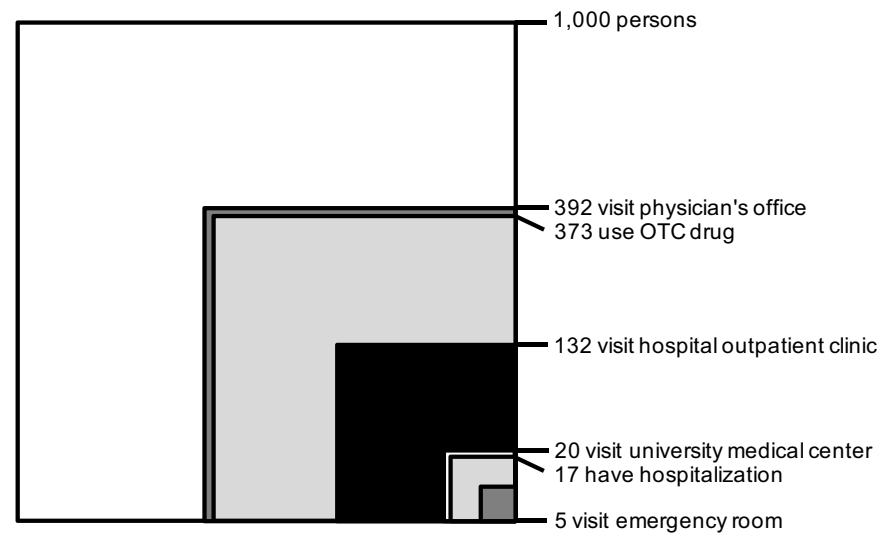

2021

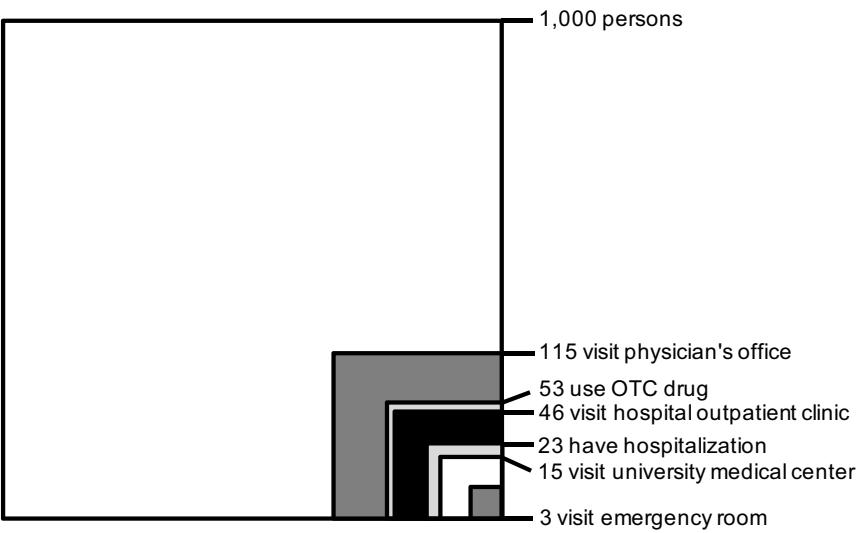

Figure 2 Comparison of health care utilization among elderly ( $\geq 65$ years old) between the previous study in $2013^{15}$ and the present study in 2021.

hospitalizations were at the same level as those before the pandemic. Although a cross-sectional survey is a common method for conducting the ecology of medical care studies, ${ }^{8,9,11}$ health care utilization may be underestimated compared with a health diary method, which was used in previous studies in Japan. ${ }^{14,15}$ However, the changes in health care utilization were drastic and cannot be explained by differences in the methods alone.

One of the causes of the decline in OTC drug use, physician's office visits, and hospital outpatient clinic visits may be the decreased number of common infectious diseases due to the prevention measures against the spread of infection such as hygiene and physical distancing policies. ${ }^{25,26}$ An increase in the threshold for health care utilization due to fear of being infected by COVID-19 at medical facilities may also have caused these results. ${ }^{3}$ Because Japanese residents tend to be more risk-averse than those in other countries, ${ }^{27}$ the risk preference for COVID-19 infection may have influenced health care utilization, especially among the elderly who are at higher risk of experiencing severe infection. In Japan, because the application and spread of telemedicine have been slow even during the pandemic, ${ }^{28}$ access to care, especially for new health-related events, is impaired in the population. Thus, it is necessary to improve access to health care by telemedicine expansion while considering the quality and safety of care and usability.

Our study also reported the association between social isolation, which is a major health problem and has increased globally due to the pandemic, and health care utilization. The health care utilization of socially isolated people during the pandemic has been unclear worldwide. The results of this study indicated that a pharmacy is an important source of health care in the population with social isolation during the pandemic. A previous study showed that social isolation was

Table 3 Adjusted Odds Ratio $(95 \%$ CI) for Health Care Utilization by Sociodemographic and Clinical Factors $(N=1747)$

\begin{tabular}{|c|c|c|c|}
\hline & OTC drug use & Office visit & Hospital visit $^{*}$ \\
\hline \multicolumn{4}{|l|}{ Age } \\
\hline $20-64$ & Reference & Reference & Reference \\
\hline$\geqq 65$ & $0.66(0.38-1.11)$ & $0.89(0.58-1.34)$ & $1.02(0.58-1.74)$ \\
\hline \multicolumn{4}{|l|}{ Gender } \\
\hline Male & Reference & Reference & Reference \\
\hline Female & $1.44(1.02-2.04)^{\dagger}$ & $1.55(1.12-2.15)^{\dagger}$ & $0.88(0.56-1.37)$ \\
\hline \multicolumn{4}{|l|}{ Education } \\
\hline Less than or equal to high school & Reference & Reference & Reference \\
\hline More than high school & $1.69(1.16-2.52)^{\dagger}$ & $0.87(0.63-1.20)$ & $0.73(0.46-1.14)$ \\
\hline \multicolumn{4}{|l|}{ Annual household income, million JPY } \\
\hline$<3.00(\fallingdotseq 27,000$ US dollars $)$ & Reference & Reference & Reference \\
\hline $3.00-4.99$ & $1.15(0.67-2.03)$ & $1.04(0.66-1.66)$ & $1.74(0.88-3.73)$ \\
\hline$\geqq 5.00$ & $1.10(0.66-1.91)$ & $0.87(0.55-1.39)$ & $1.69(0.85-3.64)$ \\
\hline \multicolumn{4}{|l|}{ Social isolation } \\
\hline Absent & Reference & Reference & Reference \\
\hline Present & $1.49(1.03-2.13)^{\dagger}$ & $0.92(0.64-1.29)$ & $1.10(0.67-1.76)$ \\
\hline \multicolumn{4}{|l|}{ Number of chronic conditions } \\
\hline 0 & Reference & Reference & Reference \\
\hline 1 & $0.84(0.55-1.26)$ & $1.32(0.90-1.92)$ & $2.47(1.39-4.48)^{\dagger}$ \\
\hline$\geqq 2$ & $0.76(0.46-1.22)$ & $1.25(0.82-1.90)$ & $3.26(1.80-6.00)^{t}$ \\
\hline
\end{tabular}

OTC over the counter

"Included hospital outpatient clinic visit, university medical center visit, and emergency room visit

'Significant difference, $P<.05$ 
associated with negative patient experience in primary care clinics. ${ }^{29}$ Therefore, in the COVID-19 era, strengthening the primary care function of pharmacies as more accessible gateways for medical care may be effective in improving the quality of care and health outcomes in socially isolated populations. For example, in the USA, the utility of retail clinics in pharmacies is gradually gaining attention. ${ }^{30}$ In Japan, the Ministry of Health, Labor and Welfare established a new "Health Support Pharmacy" system in 2016 and is now promoting the reinforcement of primary care and health support functions of community pharmacies. ${ }^{31}$ In addition, we observed that women were more likely to visit a physician's office, and patients with chronic conditions were more likely to visit a hospital. These findings were consistent with those of previous studies conducted before the COVID-19 pandemic. . $^{10,15,32}$

This is the first study to report the ecology of medical care in the general Japanese population during the COVID-19 pandemic. The ecology of the medical care model is a useful framework for understanding the patterns of an individual's choices in seeking medical care for health-related events. A key strength of our study is the use of data from a nationwide study, with a sample representative of the Japanese adult population, which allows for generalization of its results to the wider population. Another strength of this study is the high response rate.

The present study has several limitations. First, the survey was retrospective, and the questions about health care utilization were asked with respect to the last month; thus, recall biases could have affected our results. Second, our data were collected during a single month, and seasonal variation of disease incidence may result in estimates that are different from the present study. Third, we compared the results of the present study with the ecology of medical care study conducted in 2013 before the pandemic. Because of the 8-year inter$\mathrm{val}$, it is possible that factors other than the pandemic have also affected health care utilization. However, there have been no reports of changes in Japan's healthcare systems that have drastically altered healthcare utilization during this period. Fourth, we could not perform any statistical tests to compare the ecology of medical care between time periods because we used the aggregate data of the study conducted in 2013 for comparison, and not individual participant data. Fifth, we used a validated list of chronic conditions; however, self-reported data for identifying chronic conditions may have introduced misclassification bias.

\section{CONCLUSIONS}

Our ecology of medical care study during the COVID-19 pandemic in Japan revealed that the use of medical facilities for health-related events decreased drastically, especially among the elderly, compared with the pre-pandemic levels. Moreover, a pharmacy is an important source of health care in a population with social isolation during the pandemic. These findings may be useful to researchers and policymakers in rethinking health care systems during and after the pandemic.

Corresponding Author: Takuya Aoki, MD, PhD, MMA; Division of Clinical Epidemiology, Research Center for Medical Sciences, The Jikei University School of Medicine, Tokyo, Japan (e-mail: taoki@jikei. ac.jp).

Supplementary Information The online version contains supplementary material available at https://doi.org/10.1007/s11606-02207422-7.

Funding This work was supported by JSPS KAKENHI Grant Number JP2OK18849.

\section{Declarations:}

Conflict of Interest: Drs. Aoki and Matsushima received lecture fees and lecture travel fees from the Centre for Family Medicine Development of the Japanese Health and Welfare Co-operative Federation. Drs. Aoki and Matsushima are advisers of the Centre for Family Medicine Development practice-based research network. Dr. Matsushima's sonin-law worked at IQVIA Services Japan K.K. which is a contract research organization and a contract sales organization. Dr. Matsushima's son-in-law works at SYNEOS HEALTH CLINICAL K.K. which is a contract research organization and a contract sales organization.

\section{REFERENCES}

1. Alexander GC, Tajanlangit M, Heyward J, Mansour O, Gato DM, Stafford RS. Use and Content of Primary Care Office-Based vs Telemedicine Care Visits During the COVID-19 Pandemic in the US. JAMA Netw Open. 2020;3(10):e2021476.

2. Whaley CM, Pera MF, Cantor J, et al. Changes in Health Services Use Among Commercially Insured US Populations During the COVID-19 Pandemic. JAMA Netw Open. 2020;3(11):e2024984.

3. Takakubo, T, Odagiri, Y, Machida, M, et al. Changes in the medical treatment status of Japanese outpatients during the coronavirus disease 2019 pandemic [published online March 16, 2021]. J Gen Fam Med. 2021;22(5):246-261. https://doi.org/10.1002/jgf2.432.

4. Xu S, Glenn S, Sy L, et al. Impact of the COVID-19 Pandemic on Health Care Utilization in a Large Integrated Health Care System: Retrospective Cohort Study. J Med Internet Res. 2021;23(4):e26558.

5. World Health Organization. Coronavirus Disease (COVID-19): Herd Immunity, Lockdowns and COVID-19. https://www.who.int/newsroom/q-a-detail/herd-immunity-lockdowns-and-covid-19. Accessed July 10, 2021.

6. Office for Novel Coronavirus Disease Control, Cabinet Secretariat, Government of Japan. COVID-19 Information and Resources. https:// corona.go.jp/en/. Accessed December 8, 2021.

7. White KL, Williams TF, Greenberg BG. The ecology of medical care. N Engl J Med. 1961;265:885-892.

8. Green LA, Fryer GE Jr, Yawn BP, Lanier D, Dovey SM. The ecology of medical care revisited. N Engl J Med. 2001;344(26):2021-2025.

9. Johansen ME, Richardson CR. The Ecology of Medical Care Before and After the Affordable Care Act: Trends From 2002 to 2016. Ann Fam Med. 2019;17(6):526-537.

10. Ferro A, Kristiansson PM. Ecology of medical care in a publicly funded health care system: a registry study in Sweden. Scand J Prim Health Care. 2011;29(3):187-192.

11. Xiong $\mathbf{X}$, Cao $\mathbf{X}$, Luo $\mathbf{L}$. The ecology of medical care in Shanghai. BMC Health Serv Res. 2021;21(1):51.

12. Shao CC, Chang CP, Chou LF, Chen TJ, Hwang SJ. The ecology of medical care in Taiwan. J Chin Med Assoc. 2011;74(9):408-12. 
13. Sakamoto H, Rahman M, Nomura S, et al. Japan health system review. World Health Organization. Regional Office for South-East Asia. 2018. https://apps.who.int/iris/handle/10665/259941. Accessed December 8, 2021.

14. Fukui T, Rhaman M, Takahashi O, et al. The ecology of medical Care in Japan. JMAJ. 2005;48(4):163-167.

15. Fukui T, Rahman M, Ohde S, Hoshino E, Kimura T, Urayama KY, Omata F, Deshpande GA, Takahashi O. Reassessing the Ecology of Medical Care in Japan. J Community Health. 2017;42(5):935-941.

16. Wu B. Social isolation and loneliness among older adults in the context of COVID-19: a global challenge. Glob Health Res Policy. 2020;5:27.

17. Leigh-Hunt N, Bagguley $\mathbf{D}$, Bash $\mathbf{K}$, et al. An overview of systematic reviews on the public health consequences of social isolation and loneliness. Public Health. 2017;152:157-171.

18. Mosen DM, Banegas MP, Tucker-Seeley RD, et al. Social Isolation Associated with Future Health Care Utilization. Popul Health Manag. 2021;24(3):333-337.

19. Our World in Data. Japan: Coronavirus Pandemic Country Profile. https://ourworldindata.org/coronavirus/country/japan\#. Accessed December 8, 2021.

20. Nippon Research Center. Nippon Research Center. https://www.nrc.co. jp/english/index.html. Accessed December 8, 2021.

21. Ministry of Health, Labour and Welfare. The 15th study group on the review of guidelines for the appropriate implementation of telemedicine. https://www.mhlw.go.jp/content/10803000/000786235.pdf. Accessed December 8, 2021.

22. Kurimoto A, Awata S, Ohkubo T, et al. Reliability and validity of the Japanese version of the abbreviated Lubben Social Network Scale. Nihon Ronen Igakkai Zasshi. 2011;48(2):149-157.

23. Lubben J, Blozik E, Gillmann G, et al. Performance of an abbreviated version of the Lubben Social Network Scale among three European community-dwelling older adult populations. Gerontologist. 2006;46(4):503-513.

24. Fortin M, Almirall J, Nicholson K. Development of a research tool to document self-reported chronic conditions in primary care. J Comorb. 2017;7(1):117-123.

25. Fricke LM, Glöckner S, Dreier M, Lange B. Impact of nonpharmaceutical interventions targeted at COVID-19 pandemic on influenza burden - a systematic review. J Infect. 2021 Jan;82(1):1-35.

26. Lee HH, Lin SH. Effects of COVID-19 Prevention Measures on Other Common Infections, Taiwan. Emerg Infect Dis. 2020;26(10):2509-2511.

27. Canale N, Vieno A, Lenzi M, Griffiths MD, Perkins DD, Santinello M.Cross-national differences in risk preference and individual deprivation: a large-scale empirical study. Personality and Individual Differences, 2018;126:52-60

28. Miyawaki A, Tabuchi T, Ong MK, Tsugawa Y. Age and Social Disparities in the Use of Telemedicine During the COVID-19 Pandemic in Japan: Cross-sectional Study. J Med Internet Res. 2021;23(7):e27982.

29. Aoki T, Yamamoto Y, Ikenoue T, et al. Social Isolation and Patient Experience in Older Adults. Ann Fam Med. 2018;16(5):393-398.

30. Chang JE, Brundage SC, Chokshi DA. Convenient Ambulatory CarePromise, Pitfalls, and Policy. N Engl J Med. 2015;373(4):382-388.

31. Hirota N, Okamura N. Patients' Attitudes, Awareness, and Opinions About Community Pharmacies in Japan: Next Steps for the Health Support Pharmacy System. Integr Pharm Res Pract. 2020;9:243-256.

32. Glynn LG, Valderas JM, Healy $\mathbf{P}$, et al. The prevalence of multimorbidity in primary care and its effect on health care utilization and cost. Fam Pract. 2011;28(5):516-23.

Publisher's Note: Springer Nature remains neutral with regard to jurisdictional claims in published maps and institutional affiliations. 